\title{
Juzgado sin papel, un paso más de la justicia electrónica*
}

\section{Myrna Elia García Barrera**}

\begin{abstract}
RESUMEN
El objetivo de la presente investigación es conocer la implementación del Juzgado sin papel en el Poder Judicial de Nuevo León, sus objetivos, su ejecución y alcance, mismo que tiene como base el aprovechamiento de las herramientas tecnológicas en la sustanciación de procesos judiciales con el fin de dar comienzo a la migración vivencial de manera ordenada y dictaminada del expediente físico al expediente electrónico o digital, con la caracteristica operativa de ser juzgado sin papel.
\end{abstract}

\section{PALABRAS CLAVE}

Juzgado sin papel, expediente electrónico, facilidad en el almacenamiento y búsqueda de la información, eficiente impartición de justicia.

\section{ABSTRACT}

The objective of the present research is to be acquainted with the implementation of the Court without paper in the Judicial Power of Nuevo León, its objectives, its execution and scope, which is based on the use of technological tools in the substantiation of judicial processes for the purpose of initiating the migratory experience in an orderly and determined manner from the physical file to the electronic or digital file, with the operative characteristic of being judged without paper.

\section{KEYWORDS}

Law, Privacy, Company, Information, Personal Data, Digital Media.

*Artículo recibido el 17 de junio de 2017 y aceptado el 25 de septiembre de 2017

**Poder Judicial del Estado de Nuevo León, Facultad de Derecho y Criminologia, UANL, Universidad de Monterrey. (myrgarcia@hotmail.com) 


\section{Introducción}

Cibersociedad, ciberespacio, ciberciudadanos, homo digitalis, comunidades virtuales, redes telemáticas, e-democracia, e-elections, politica.com son términos que se presentan en el discurso glorificador de las nuevas tecnologías, del progreso electrónico; saludan a la sociedad posindustrial. Al Gore, desde la vicepresidencia norteamericana, anunciaba "la nueva era de la democracia". Internet garantiza la democracia interactiva, virtual, planetaria, directa, por sondeo y votación electrónica. ${ }^{1}$

Es evidente que en todo aparecen las nuevas tecnologías de la información y de la comunicación, provocando una serie de revoluciones e innovaciones, pero también de disputas en cuanto a los acomodos y aceptación de las mismas. Así, se hace patente que las fronteras y límites del conocimiento se rompen gracias a la información del tipo que sea y que puede fluir de cualquier punto del planeta, donde se encuentre un ser humano con deseos de expresarse y voluntad de ser leído, oído u observado por otro o por todos.

Ahora bien, conscientes de las nuevas aplicaciones jurídicas en la sociedad de la información, es indudable la importancia del tema de la modernización judicial al utilizar medios electrónicos o telemáticos, y también desde qué momento se tiene por aceptado el contenido del propio documento electrónico o telemático. Durante mucho tiempo, la contratación ha servido de fórmula para garantizar la prueba de su existencia. ${ }^{2}$

Internet es un ejemplo de los instrumentos y aportaciones que nos proporciona este mundo digital o mundo virtual, pero con repercusiones en el mundo real, de tal magnitud que influye en los siguientes aspectos de la humanidad:

\footnotetext{
1 LOZAdA, Mireya, "Politica en red y democracia virtual: la cuestión de lo público", Estudios Latinoamericanos sobre cultura y transformaciones sociales en tiempos de globalización 2, Buenos Aires, Clacso, 2001. [Consulta: 20 de mayo, 2017]. Disponible en: http://biblioteca.clacso.edu.ar/clacso/gt/20100914034214/10lozada.pdf

2 Perales Sanz, José Luis, La seguridad jurídica en las transacciones electrónicas, Seminario del Consejo General del Notariado en la UIMP, Madrid, Civitas, 2002.
} 
forma de pensar; forma de conocer y entender el mundo; forma de relacionarnos. En lo general, se habla de una forma de cultura global, mismo que debemos de llevarnos al gobierno electrónico para el beneficio de todas las personas.

Existen tendencias orientadas a revisar y modificar la regulación sobre la jurisdicción, ejecución y entrada en vigor, competencia judicial y legislación aplicable en los contratos realizados a través de medios telemáticos. Se busca ajustarla a la legislación del país de destino, lo que significaría que cualquier entidad que ofrece sus productos o servicios por internet debe estar en condiciones para cumplir con las legislaciones de todos los países. En la práctica esto puede resultar imposible y, consecuentemente, limita el desarrollo del comercio electrónico y el mercado interior sin fronteras.

Como ya se sabe, el consentimiento es un elemento esencial en la existencia del acto jurídico. Se define como una expresión de voluntad, si el acto es unilateral, es decir, que en el mismo intervenga tan solo una voluntad; o bien, la expresión de un consentimiento o acuerdo con dos o más voluntades, si en el mismo participan dos o más voluntades. Por otro lado:

El objeto no constituye la materia 'de la cual' se hace una cosa, sino materia 'sobre la cual' recae la acción, que al mismo tiempo hace las veces de forma, puesto que específica la acción, de aquí se puede decir, que el objeto entendido como forma y término del acto jurídico en cuestión, nos explica claramente cómo es el acto jurídico objeto de estudio, es decir, el consentimiento manifestado. ${ }^{3}$

Ahora bien, en este contexto:

El ciberespacio también necesita una ciber-justicia. Cada vez se demuestra la incompatibilidad existente entre el mundo de las tecnologías de la información, la nueva economía y su mercado y la justicia ordinaria lenta, saturada y poco eficaz en muchas ocasiones, por todo ello, se hace necesaria una pronta adecuación a las nuevas necesidades. ${ }^{4}$

\footnotetext{
${ }^{3}$ Perales Sanz, José Luis, La seguridad jurídica en las transacciones electrónicas, Seminario del Consejo General del Notariado en la UIMP, Madrid, Civitas, 2002, p. 21.

${ }^{4}$ Perales Sanz, José Luis, La seguridad juridica en las transacciones electrónicas, Seminario del Consejo General del Notariado en la UIMP, Madrid, Civitas, 2002.
} 
Estos nuevos conceptos de justicia electrónica, ciberjustica, justicia en línea necesitan un marco institucional y normativo para su regulación, con políticas públicas claras, para que sean una alternativa positiva, eficaz y real. ${ }^{5}$

En la presente investigación, señalaremos el tránsito hacia la justicia sin papel, como objetivo primordial de la modernización judicial, en beneficio de los y las justiciables.

\section{Justicia electrónica}

Toda sociedad está integrada por un número de personas cuyo comportamiento se traduce en una serie de relaciones entre sí, que exigen a su conducta manifestarse de manera coordinada y recíproca, en un entorno de respeto. Sin embargo, es imposible evitar los conflictos. Ante una situación concreta de conflicto, la persona pone en práctica los conocimientos que ha adquirido durante su vida, innovando el camino hacia la definición de su conducta y en la persecución de sus fines. En esa búsqueda constante, algunos procedimientos resultan inútiles e inoperantes, a diferencia de otros cuya eficacia los hace idóneos para la resolución del momento.

No es conveniente que todos los usos sociales sean retomados por el derecho y se formulen a través de normas jurídicas. Es decir, la importancia y el impacto social que reviste cada una de las acciones varía en grado de mayor a menor trascendencia para la convivencia social. Por lo tanto, el derecho sólo deberá tomar aquellas que permitan la existencia y desarrollo pacífico y ordenado, dotándolas de obligatoriedad. Para aquellos usos sociales retomados por el derecho, la obligatoriedad no les es esencial, sino circunstancial, pues deriva del orden jurídico. De la misma forma, no obstante que la norma jurídica se presenta obligatoria, y en algunas ocasiones no es necesaria ni verdadera, ya que se basa en preceptos normativos neutrales. ${ }^{6}$

Los usos sociales abarcan la práctica totalidad de las conductas aprendidas socialmente, que son ni más ni menos los que cotidianamente se ejercitan en el mundo de la relación social, todas aquellas que sirven

\footnotetext{
${ }^{5}$ Montesinos Garcia, Ana, "Cuestiones actuales de derecho y tecnologias de la información y la comunicación (tic)", Revista Aranzadi Derecho de las Nuevas Tecnologías, núm. 4, p. 396.

${ }^{6}$ Uno de los elementos de juzgar con perspectiva de género conforme a la jurisprudencia número 22/2016. "Tesis Jurisprudencial número 22/2016 de la Primera Sala de la Suprema Corte de Justicia de la Nación", Suprema Corte de Justicia de la Nación. Consulta: 20 de mayo, 2017]. Disponible en: https://sjf.scjn.gob.mx/sjfsist/paginas/DetalleGeneralV2.aspx?Clase $=$ DetalleTesisBL\&tI $=2011430 \&$ Semanario $=0$
} 
al ser humano para sobrevivir y desenvolverse en grupo. Y el derecho es un procedimiento que convierte en obligatorias algunas de sus conductas, muchas de las cuales ya se vienen realizando con sentido normativo mucho antes de que ningún ordenamiento las contemple. ${ }^{7}$

De primordial importancia resulta poder determinar cuándo un uso social se tiene que expresar en una norma de derecho, puesto que la obligatoriedad conlleva atentar contra la libertad del individuo y con ello impedir su capacidad creativa. Para ello, es indispensable atender dos aspectos fundamentales. El primero consiste en brindarle al individuo una esfera protegida donde las acciones de los demás, entiéndase particulares y autoridades, no interferirán en sus aspiraciones.

El criterio para delinear esa esfera protegida no es tan sólo enumerarle una serie de derechos subjetivos sino, además:

Sustraer al control de los demás algunos de los principios directivos de sus acciones. Al determinar, dónde se deberán trazar las líneas divisorias de la esfera protegida, la cuestión importante es si las acciones de otras personas que nosotros deseamos impedir se interpondrán realmente en las expectativas razonables de la persona protegida. ${ }^{8}$

Un segundo criterio deriva del carácter axiológico del derecho. Las normas jurídicas son enunciados obligatorios con sentido de valor. De la reflexión de los usos sociales, las personas concluyen que sus acciones están encaminadas a la satisfacción de sus necesidades, algunas mediatas, otras inmediatas, pero todas ellas producto de su sociabilidad. Estas necesidades se pueden representar por medio de los valores humanos; algunos son supremos (la justicia, la igualdad, el bien, la libertad, la equidad) y otros son inferiores (la utilidad, la oportunidad, lo práctico, la economía, la eficacia, la protección).

Se puede inferir de lo anterior que un uso social tiene que ser contemplado por una norma de derecho cuando hay que garantizar su realización, es decir, cuando haya un fin generalmente aceptado, y con la protección de los derechos humanos.

No basta con que en una sociedad exista un orden jurídico para afirmar que en ella se vive bajo un Estado de derecho. Para que esto sea así, las normas

\footnotetext{
${ }^{7}$ Pérez Ruiz, Carlos, La construcción social del derecho, España, Universidad de Sevilla, 1996, p. 58.

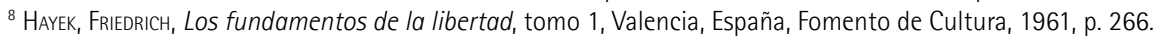


jurídicas y el derecho en su conjunto deben reunir ciertas características que deriven en su certeza. La situación en que se encuentra toda persona en relación con la sociedad debe ser retributiva. Para realizarse por medio de la acción, necesita fincar su actividad en la creencia en la vida social; la sociedad, por su parte, debe proporcionarle la garantía que da la confianza, es decir, la certeza de la debida protección de los derechos humanos.

Sería incorrecto hablar de una certeza social. La certeza corresponde al mundo individual, personal, inclusive psicológico. Es una sensación de convicción de contar con la verdad de un conocimiento. "El problema de la certeza es el problema del particular, el problema del individuo, considerado tal cual es él, rebelde a toda reducción universalista: con su destino absolutamente individual, en su situación personalísima, ligado a su singularidad, que no piensa abandonar ni puede perder". ${ }^{9}$

Lo que la experiencia jurídica aporta a la sociedad es la confianza en que finca la persona su acción presente en la búsqueda de un mejor futuro. En este sentido, la certeza es sinónimo de previsión introducida al conocimiento (saber es prever). La certeza le brinda a la persona una herramienta para encaminar sus actos de conformidad con lo históricamente aceptado. Se dice una herramienta porque "La importancia de la certeza no radica en las bondades propias de las normas, que la proporcionan, sino en el hecho de que esta situación actúa como instrumento necesario para la realización de otros fines, es decir, su valor es instrumental". ${ }^{10}$ Aquí el contenido de la norma es irrelevante, lo importante es que, gracias a su obligatoriedad, permite a las personas encausar su obrar en una dirección objetiva, evitando la vaguedad y sobre todo la arbitrariedad.

Hay que precisar que la certeza del derecho es de naturaleza legal y no necesariamente absoluta. "Al fijar a los hombres solamente algunas de las condiciones de sus acciones, el legislador suministra oportunidades y posibilidades, pero nunca certezas en lo que respecta a los resultados individuales." ${ }^{11}$ Esto es así porque las normas jurídicas deben estar elaboradas de tal manera que representen para la persona sólo datos adicionales de cómo actuar, sin que esto menoscabe su esfera protegida, para que pueda alcanzar sus propios fines. El derecho no implica la implantación de un orden particular, sino el sentar las bases para que se dé un orden, cualquiera que éste sea, en la sociedad a través de una regularidad limitada.

\footnotetext{
${ }^{9}$ López de Oñate, Flavio, La certeza del derecho, Buenos Aires, Argentina, Ediciones Jurídicas Europa-América, 1953, p. 55.

${ }^{10}$ Azúa Reyes, Sergio, Los principios generales del derecho, México, Porrúa, 2001, p. 154.

${ }^{11}$ Hayek, Friedrich, Los fundamentos de la libertad, tomo 1, Valencia, España, Fomento de Cultura, 1961, p. 288.
} 
De acuerdo con su función instrumental, la certeza del derecho pone a la persona en condiciones suficientes para planear su vida. Le permite tomar sus decisiones en la medida de sus propias posibilidades, pero aprovechando las capacidades y acciones de sus semejantes.

Se puede definir la certeza del derecho desde el punto de vista de la enumeración de sus aspectos como:

Un estado subjetivo del gobernado, que conoce (bien sea por información o captación intuitiva que le otorga su convivencia en el ambiente general) sus posibilidades de actuar, sus limitaciones en la conducta y las consecuencias que el derecho establece, tanto en el caso de actuar dentro de ese ámbito, como en el de traspasarlo. ${ }^{12}$

Aunado a lo anterior, tendremos que señalar: "La informática es un instrumento al servicio del Derecho. Contribuye a acelerar y a hacer más eficiente algunas labores tradicionales del jurista. Pero es más que un instrumento en la medida que ofrece resultados que no sería posible de otro modo". ${ }^{13}$

Si se utiliza la informática en la teoría de la decisión en materia judicial, ${ }^{14}$ los juzgadores podrían quedar definitivamente aislados y privados de toda capacidad de influencia. Por lo tanto, en esta vinculación de la ciencia de la computación y la ciencia del derecho, específicamente en el terreno definitivo por la relación entre decisión judicial e informática, nos quedan una serie de dudas en los aspectos vinculados a la adaptación de herramientas preconstruidas. Asimismo, quedan dudas sobre temas de instrumentación de soluciones puntuales, es decir, si se logrará la automatización de las inferencias y decisiones judiciales. Esto pone en evidencia la importancia de impulsar transformaciones conceptuales de relevancia en la teoría de la decisión judicial.

Cabe destacar el papel preponderante de la información ${ }^{15}$ en este proceso y el manejo inteligente de la misma, o sea, que la información sea ofrecida oportunamente al decidor. En el caso de las decisiones judiciales, la información no puede servir sólo para lograr una buena justificación y argumentación de las sentencias. Debe cumplir un papel activo en la corrección de las probabilidades a priori que les sirven de base, y en la distribución de la

\footnotetext{
${ }^{12}$ Azúa Reyes, Sergio, Los principios generales del derecho, México, Porrúa, 2001, p. 153.

${ }^{13}$ Fix Fierro, Héctor y Muñoz de Alba, Marcia, "El sistema unam-Jure. Hoy", Diálogos sobre Informática Juridica, p. 41. [Consulta: 27 de mayo, 2017]. Disponible en: https://archivos.juridicas.unam.mx/www/bjv/libros/2/723/5.pdf

${ }^{14}$ BarRagán, Julia, Informática y decisión judicial, México, Fontamara, 1994, p. 14.

${ }^{15}$ Barragán, Julia, Informática y decisión judicial, México, Fontamara, 1994, pp. 14 y ss.
} 
información y el desarrollo de mecanismos de interacción de múltiples usuarios con el sistema. Así lograremos otra manera de manejar inteligentemente la información.

Para lograr manejarnos con información y no sólo con datos, debemos considerar que: "El soporte fundamental de la informática jurídica se finca en la lógica y la ingeniería de programación, las cuales tienen a su cargo por una parte establecer las reglas de validación general y por la otra desarrollar los algoritmos más apropiados para el manejo de la información". ${ }^{16}$

El Código de Comercio define a la firma electrónica como los datos en forma electrónica consignados en un mensaje de datos, o adjuntados o lógicamente asociados al mismo por cualquier tecnología, que son utilizados para identificar al firmante en relación con el mensaje de datos. Así, indica que el firmante aprueba la información contenida en el mensaje de datos, y que produce los mismos efectos jurídicos que la firma autógrafa. Por tanto, es admisible como prueba en juicio.

El Código de Comercio refuerza los efectos de la firma electrónica, al establecer que no se negarán efectos jurídicos, validez o fuerza obligatoria a cualquier tipo de información por la sola razón de que esté contenida en un mensaje de datos.

Por otra parte, la Ley Federal del Procedimiento Contencioso Administrativo define en el siguiente artículo, el cual fue casi en su totalidad adicionado el 30 de mayo del año 2002, cuándo los medios electrónicos comenzaron a formar parte de nuestra legislación.

Artículo 69-C. Los titulares de las dependencias u órganos administrativos desconcentrados y directores generales de los organismos descentralizados de la administración pública federal podrán, mediante acuerdos generales publicados en el Diario Oficial de la Federación, establecer plazos de respuesta menores dentro de los máximos previstos en leyes o reglamentos y no exigir la presentación de datos y documentos previstos en las disposiciones mencionadas, cuando puedan obtener por otra vía la información correspondiente.

En los procedimientos administrativos, las dependencias y los organismos descentralizados de la Administración Pública Federal recibirán las promociones o solicitudes que, en términos de esta Ley, los y las justiciables presenten por escrito, sin perjuicio de que dichos documentos

\footnotetext{
${ }^{16}$ Barragán, Jula, Informática y decisión judicial, México, Fontamara, 1994, p. 36.
} 
puedan presentarse a través de medios de comunicación electrónica en las etapas que las propias dependencias y organismos así lo determinen mediante reglas de carácter general publicadas en el Diario Oficial de la Federación. En estos últimos casos se emplearán, en sustitución de la firma autógrafa, medios de identificación electrónica.

El uso de dichos medios de comunicación electrónica será optativo para cualquier interesado, incluidos los y las justiciables que se encuentren inscritos en el Registro de Personas Acreditadas a que alude el artículo 69-B de esta Ley.

Los documentos presentados por medios de comunicación electrónica producirán los mismos efectos que las leyes otorgan a los documentos firmados autógrafamente y, en consecuencia, tendrán el mismo valor probatorio que las disposiciones aplicables les otorgan a éstos.

La certificación de los medios de identificación electrónica del o la promovente, así como la verificación de la fecha y hora de recepción de las promociones o solicitudes y de la autenticidad de las manifestaciones vertidas en las mismas, deberán hacerse por las dependencias $u$ organismos descentralizados, bajo su responsabilidad, y de conformidad con las disposiciones generales que al efecto emita la Secretaría de Contraloría y Desarrollo Administrativo.

Las dependencias y organismos descentralizados podrán hacer uso de los medios de comunicación electrónica para realizar notificaciones, citatorios o requerimientos de documentación e información a los particulares, en términos de lo dispuesto en el artículo 35 de esta Ley.

Asimismo, la propia ley establece en su artículo 1-A: "XIII. Juicio en línea: Substanciación y resolución del juicio contencioso administrativo federal en todas sus etapas, así como de los procedimientos previstos en el artículo 58 de esta Ley, a través del Sistema de Justicia en Línea, incluso en los casos en que sea procedente la vía sumaria". ${ }^{17}$

\section{Juicio en línea o tribunal virtual}

Como ya lo hemos señalado, los avances tecnológicos han otorgado beneficios no sólo en el ámbito de las ciencias exactas, sino también en el ámbito de la cibernética, de las comunicaciones. Dichas innovaciones se han ido adoptando

\footnotetext{
${ }^{17}$ Fracción reformada. Diario Oficial de la Federación, 10 de diciembre, 2010.
} 
en varias materias o áreas del conocimiento. El derecho no se ha quedado fuera de ello, y se refleja en la informática jurídica, en sus diferentes tipos.

La informática jurídica se clasifica en documental, operacional, de gestión, registral y de decisión. Sin embargo, algunos autores sólo la clasifican en tres áreas: informática documental, informática de gestión e informática de decisión. ${ }^{18}$

La primera es aquella que se encarga de realizar el almacenamiento, clasificación y orden de los datos, resoluciones, fallos, documentos, ordenamientos legislativos, así como toda la información jurídica. De esta forma, la informática jurídica documental es una herramienta que facilita el almacenamiento y búsqueda de la información con mayor agilidad.

Por su parte, la informática jurídica de gestión tiene como objetivo la creación de documentos o datos nuevos a partir de unos ya existentes. Con ello se satisface con mayor eficiencia y rapidez las necesidades de los abogados, tanto en el ámbito privado como en el público.

Finalmente, la informática jurídica decisoria:

Es el segmento de la informática jurídica que procura proponer o adoptar soluciones apropiadas para casos concretos que se le planteen, valorando los datos de cada problema por comparación con los criterios de decisión que se le hayan provisto. Con el debido respeto, trata de hacer por medio del ordenador lo que con su cerebro, hacen hoy, los encargados de adoptar decisiones jurídicas especialmente cuando se trata de decisiones de rutina sujetas a modos de solución suficientemente conocidos. ${ }^{19}$

"La informática decisoria suele presentarse a sí misma como una colección de métodos, medios y propuestas para auxiliar al decidor humano en su tarea, antes que para reemplazarlo." ${ }^{20}$ Aun a pesar de las ventajas que dicha herramienta nos otorga, es importante mencionar que muchos juristas se oponen ante la idea del uso de la justicia electrónica, ya que creen que las computadoras, con la ayuda de la inteligencia artificial, van a reemplazar a las y los juzgadores.

\footnotetext{
${ }^{18}$ Téllez Valdés, Julio, Derecho informático, México, unam, pp. 14 y ss. [Consulta: 25 de mayo, 2017]. Disponible en: https://archivos.juridicas.unam.mx/www/bjv/libros/1/313/4.pdf

${ }^{19}$ Guibourg, Ricardo, Allende, Jorge y Campanella, Elena, Manual de informática jurídica, Argentina, Astrea, 1996, pp. 11 y 12.

${ }^{20}$ Guibourg, Ricardo, Alende, Jorge y Campanella, Elena, Manual de informática jurídica, Argentina, Astrea, 1996, p. 151.
} 
Es menester señalar que las tecnologías de la información y la comunicación también permiten el trabajo colaborativo, el cual persigue favorecer el intercambio de información entre operadores, así como el trabajo en común en el seno de una comunidad de usuarios. Las herramientas de trabajo colaborativo permiten la gestión en común de tareas, la creación de foros de discusión, la elaboración de listas de distribución o la puesta en común de documentos. Como ejemplo, resulta interesante referirse a la Red Iberoamericana de Información y Documentación Judicial (Iberius). A disposición de todos los integrantes del poder judicial de Iberoamérica, se constituye como una comunidad de cooperación, concertación y apoyo recíproco. ${ }^{21}$

Sin embargo, se debe aclarar que el uso de las computadoras y de programas computacionales como auxiliares en la impartición de justicia presenta la oportunidad de "adoptar en casos diferentes numerosas decisiones, de manera previsible, confiable y extremadamente rápida”, ${ }^{22}$ aun cuando implica la solución del gran problema de "determinar el tipo de problema a resolver, establecer los límites a la diversidad de los casos, explicitar todos los criterios a emplear en las decisiones y, al menos en principio, atenerse a los resultados". ${ }^{23}$

También, es menester aclarar que, en la actualidad es impensable diseñar un programa que ejecute el procedimiento completamente, ya que es indispensable el razonamiento humano para valorar, interpretar y argumentar una gran diversidad de hechos o situaciones que se pueden presentar. Sin embargo, se han establecido criterios respecto a las funciones específicas en las que puede ser de gran utilidad para el juzgador, como la individualización judicial de la pena en materia penal, o la cuantificación de los daños y perjuicios solicitados en un caso específico.

Aunado a lo anterior, surge el cuestionamiento ¿verdaderamente existe una "justicia electrónica"? Difícilmente, se puede dar una respuesta, porque habría que revisar en que rama se estaría aplicando. La "justicia electrónica” se podrá analizar con la informática jurídica decisoria. Debido a que la informática jurídica se ha ocupado también del campo de la decisión, no es necesario que el sistema se ocupe de la decisión,

\footnotetext{
${ }^{21}$ Cerillo, Agusti, "E-justicia: las tecnologias de la información y el conocimiento al servicio de la justicia iberoamericana en el siglo xxl", Revista de Internet, Derecho y Política, núm. 4, p. 5. [Consulta: 1 de junio, 2017]. Disponible en: http://www.uoc.edu/idp/4/dt/esp/cerrillo1.pdf

${ }^{22}$ Guibourg, Ricardo, Alende, Jorge y Campanella, Elena, Manual de informática jurídica, Argentina, Astrea, 1996, p. 159.

${ }^{23}$ Guibourg, Ricardo, Alende, Jorge y Campanella, Elena, Manual de informática jurídica, Argentina, Astrea, 1996.
} 
sino simplemente puede ser una ayuda a la decisión que se puede dar 25 en varios planos y niveles. ${ }^{24}$

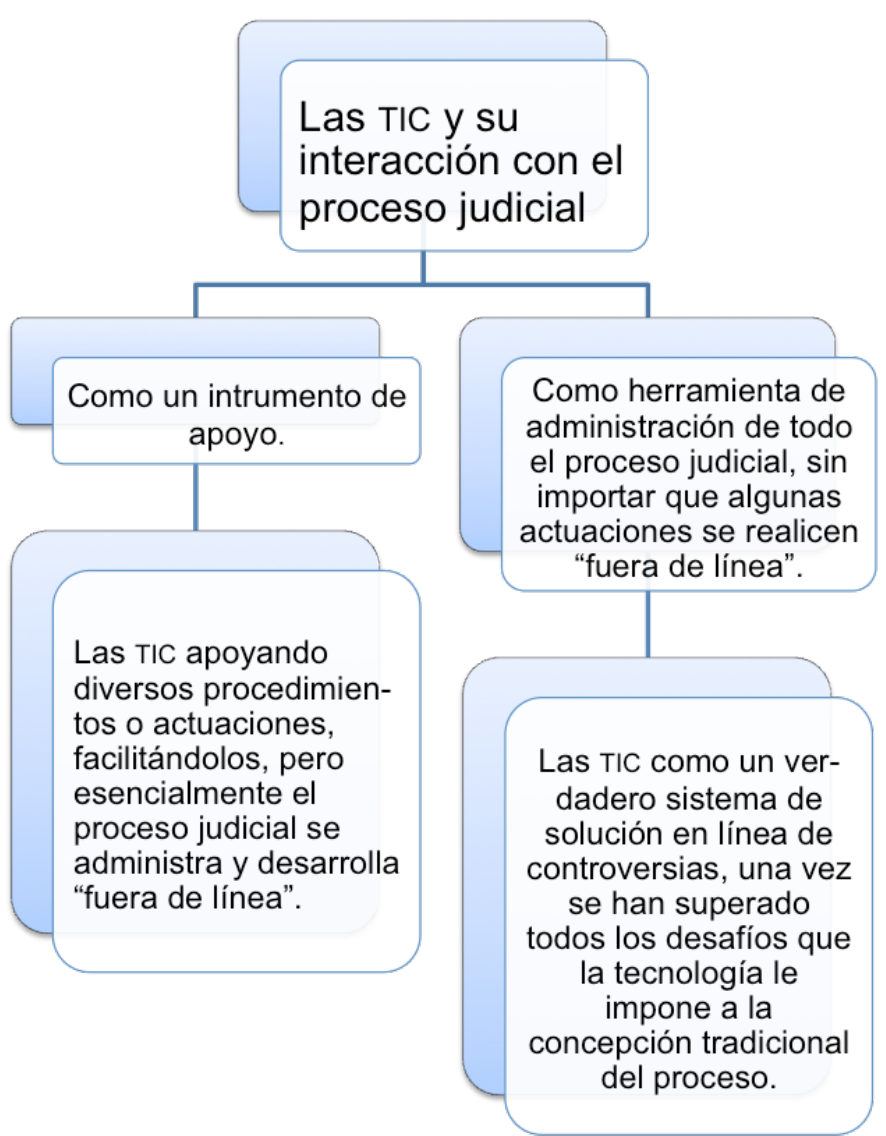

${ }^{24}$ Garcia Barrera, Myrna Elia, "Justicia electrónica o Ciber justicia, El Tribunal Virtual de Nuevo León". [Consulta: 2 de junio, 2017]. Disponible en: https://archivos.juridicas.unam.mx/www/bjv/libros/6/2958/16.pdf

${ }^{25}$ Se entiende como fuera de línea el sistema tradicional, el cual utiliza papel. Londoño SEPúlveda, Néstor Raúl, "El uso de las tic en el proceso judicial: una propuesta de justicia en línea", Revista Facultad de Derecho y Ciencias Politicas, p. 112. [Consulta: 1 de junio, 2017]. Disponible https://revistas.upb.edu.co/index.php/derecho/article/view/1033/931 
Como se observa en el esquema, las TIC en la justica tiene dos vertientes. La primera es sólo como instrumento de apoyo, ya que el sistema de impartición de justicia se administra sin ellas. La segunda es aquella donde la administración de dicha justicia se realiza en ellas, como verdadera justicia sin papel.

Ahora bien, en Estados Unidos y Europa se han profundizado el uso de las TIC a tal grado que han dejado de ser una simple herramienta para convertirse en el sustento de la solución de conflictos. Esto ha traído como consecuencia que los casos se resuelvan a través de métodos alternos de solución de conflictos completamente gestionados en línea. ${ }^{26}$

En la actualidad, las TIC son un instrumento de apoyo de la rama judicial, gracias a la utilización del sistema de gestión de la rama. Este último se encuentra implementado en las principales ciudades del país y permite que las partes hagan el seguimiento de las diferentes etapas procesales. Con ello se facilita la vigilancia de los procesos y el cumplimiento de los términos judiciales. Sin embargo, sus capacidades, alcance y escalabilidad han demostrado ser limitadas. ${ }^{27}$

Actualmente en Colombia se cuenta con un sistema de información, el cual funciona mediante una infraestructura de red privada. Únicamente permite a los usuarios externos la visualización de registros de las actuaciones ordenadas por fecha y tan sólo una referencia. Este tiene a su vez algunas limitantes: no llega a todos los despachos del país, ni sirve para generar información valiosa para realizar un seguimiento más preciso. Por lo anterior, se ha realizado una propuesta de uso de las Tic en el proceso judicial, enfocado en llevar acceso a internet a todo el país y, con ello, pasar de una infraestructura de red paralela a un sistema a través de internet que permita el acceso desde cualquier rincón del país. ${ }^{28}$

El beneficio principal al relacionar las Tic con la administración de justicia es que al sistematizar las etapas del proceso, minimizar la realización de tareas repetitivas, determinar su agenda claramente, entonces los impartidores de justicia se pueden enfocar en su función más importante: la toma de decisiones. ${ }^{29}$

${ }^{26}$ Londoño Sepúlveda, Néstor Raúl, "El uso de las tic en el proceso judicial: una propuesta de justicia en línea", Revista Facultad de Derecho y Ciencias Politicas, p. 128. [Consulta: 1 de junio, 2017]. Disponible https://revistas.upb.edu.co/ index.php/derecho/article/view/1033/931

${ }^{27}$ Londoño Sepúlveda, Néstor Raúl, "El uso de las tic en el proceso judicial: una propuesta de justicia en línea", Revista Facultad de Derecho y Ciencias Políticas. [Consulta: 1 de junio, 2017]. Disponible https://revistas.upb.edu.co/index. php/derecho/article/view/1033/931

${ }^{28}$ Londoño Sepúlveda, Néstor Raúl, "El uso de las tic en el proceso judicial: una propuesta de justicia en línea", Revista Facultad de Derecho y Ciencias Politicas, p. 132. [Consulta: 1 de junio, 2017]. Disponible https://revistas.upb.edu.co/ index.php/derecho/article/view/1033/931

${ }^{29}$ Londoño Sepúlveda, Néstor Raúl, "El uso de las tic en el proceso judicial: una propuesta de justicia en línea", Revista Facultad de Derecho y Ciencias Politicas, p. 137. [Consulta: 1 de junio, 2017]. Disponible https://revistas.upb.edu.co/ 
Existen retos importantes: suficiente capacidad de los servidores de internet, aplicaciones web bien elaboradas, soporte técnico permanente, eficiente y eficaz, un sistema amigable, seguro, compatible y presupuestal. ${ }^{30}$

Uno de los usos más beneficiosos que tienen las Tic en la administración de justicia es que a través de estas aplicaciones se puede gestionar el gran volumen de documentos que se generan o incluyen en la tramitación de los expedientes judiciales. Las herramientas de gestión documental permiten el manejo de los documentos sin la necesidad de tenerlos físicamente. ${ }^{31}$

Para avanzar en el desarrollo de la e-justicia, es necesaria la existencia del liderazgo y el impulso necesario para acometer todas las reformas que requieren las aplicaciones a que nos hemos referido en las páginas anteriores. ${ }^{32} \mathrm{El}$ proceso de desarrollo de la justicia electrónica debe ir directamente vinculado con el proceso de modernización de la propia justicia. ${ }^{33}$ Un ejemplo de ello es el llamado juzgado virtual, que analizaremos a continuación.

\section{El juzgado virtual en Nuevo León}

En el futuro, si la situación de los órganos jurisdiccionales mejora sustancialmente, será posible ver procesos judiciales en los cuales el papel sea prescindible y sea suficiente el empleo de documentos digitales. Sin embargo, parece que todavía falta mucho tiempo para implantar una administración de justicia digital. ${ }^{34}$

En el mundo las legislaciones, intentan que las TIC sean parte de la administración de justicia y con ello lograr una justicia accesible, transparente, ágil y eficiente. ${ }^{35}$

index.php/derecho/article/view/1033/931

${ }^{30}$ Londoño SEpúlveda, Néstor Raúl, "El uso de las tic en el proceso judicial: una propuesta de justicia en línea", Revista Facultad de Derecho y Ciencias Politicas, p. 140. [Consulta: 1 de junio, 2017]. Disponible https://revistas.upb.edu.co/ index.php/derecho/article/view/1033/931

${ }^{31}$ Cerrillo, Agustí. "E-justicia: las tecnologías de la información y el conocimiento al servicio de la justicia iberoamericana en el siglo XXI", Revista D'Internet, Dret I Politica, Revista de Internet, Derecho y Política, 2007, p. 7. [Consultada 1 de junio de 2017], [Disponible: http://www.uoc.edu/idp/4/dt/esp/cerrillo1.pdf].

${ }^{32}$ Cerillo, Agusti, "E-justicia: las tecnologias de la información y el conocimiento al servicio de la justicia iberoamericana en el siglo xxl", Revista de Internet, Derecho y Política, núm. 4, p. 10. [Consulta: 1 de junio, 2017]. Disponible en: http://www.uoc.edu/idp/4/dt/esp/cerrillo1.pdf

${ }^{33}$ Cerillo, Agusti, "E-justicia: las tecnologías de la información y el conocimiento al servicio de la justicia iberoamericana en el siglo xxl", Revista de Internet, Derecho y Politica, núm. 4. [Consulta: 1 de junio, 2017]. Disponible en: http://www.uoc.edu/idp/4/dt/esp/cerrillo1.pdf

${ }^{34}$ Fierro Rodriguez, Diego, "El papel es necesario en la actual Administración de Justicia", Hay Derecho. Por una conciencia cívica. [Consulta: 12 de junio, 2017]. Disponible en: http://hayderecho.com/2015/08/01/el-papel-es-necesario-en-la-actual-administracion-de-justicia/

${ }^{35}$ BuENO dE MATA, FEDERICO, "La prueba electrónica: importancia, problemática procesal y reconocimiento jurispruden- 
En palabras de González Campo, la administración judicial electrónica es un conjunto de medios o recursos organizativos jurídicos electrónicos que, mediante una ordenada y concreta implantación en la tramitación judicial, dotan a ésta de mayor eficiencia y eficacia. ${ }^{36}$ Con el uso de las tecnologías de la información y de la comunicación, la función de administrar justicia ha dado un salto cualitativo, mismo que ha situado al sistema judicial en la era de la sociedad de la información. ${ }^{37}$

En diversos países de Latinoamérica, las тic han sido pilar en la reforma judicial, misma que incluye el uso de computadoras para la realización de videoconferencias. Esto ha sido con el fin de que los testigos que se encuentran ubicados en zonas lejanas puedan declarar. ${ }^{38}$

En México, entidades federativas como Nuevo León, Chihuahua, Aguas Calientes, Hidalgo, Oaxaca o Tabasco han registrado grandes avances en el uso de las Tic en la impartición de justicia. ${ }^{39}$

Lo anterior se evidencia después de una revisión en cada portal web de los poderes judiciales de las 32 entidades federativas de la república mexicana, en el recuadro siguiente: ${ }^{40}$

cial de la prueba capital del siglo xxı", en Pilar Lasala Calleja (ed.), La administración electrónica como herramienta de inclusión digital, España, Prensas Universitarias de Zaragoza, 2011. [Consulta: 12 de junio, 2017]. Disponible en: http://www.egov.ufsc.br/portal/sites/default/files/lefis_13_ok.pdf

${ }^{36}$ González Campo, Francisco de Asis, "Arquitectura de la administración judicial electrónica española: estado actual y perspectivas de futuro", en Pilar Lasala Calleja (ed.), Derecho y Tecnologías Avanzadas, España, Prensas Universitarias Zaragoza, 2013, p. 23.

${ }^{37}$ López ValenCiA, VIRGINIA, "La justicia digital. El nuevo paradigma", Gobierno del Estado de Guerrero 2015-2021. [Consulta: 13 de junio, 2017]. Disponible en: http://i.guerrero.gob.mx/uploads/2016/02/LA-JUSTICIA-DIGITAL.pdf ${ }^{38}$ López VALENCIA, VIRGINIA, "La justicia digital. El nuevo paradigma", Gobierno del Estado de Guerrero 2015-2021. [Consulta: 13 de junio, 2017]. Disponible en: http://i.guerrero.gob.mx/uploads/2016/02/LA-JUSTICIA-DIGITAL.pdf ${ }^{39}$ López VALenCIA, VIRGINIA, "La justicia digital. El nuevo paradigma", Gobierno del Estado de Guerrero 2015-2021. [Consulta: 13 de junio, 2017]. Disponible en: http://i.guerrero.gob.mx/uploads/2016/02/LA-JUSTICIA-DIGITAL.pdf ${ }^{40}$ Elaboración propia. 


\begin{tabular}{|c|c|c|}
\hline $\begin{array}{l}\text { Entidad } \\
\text { federativa }\end{array}$ & $\begin{array}{l}\text { ¿Cuenta con tribunal } \\
\text { virtual, juicio en línea u } \\
\text { otro parecido? }\end{array}$ & Liga \\
\hline Aguascalientes & Juzgado virtual & http://www.poderjudicialags.gob.mx \\
\hline Baja California & e-tribunal & http://www.poder-judicial-bc.gob.mx \\
\hline $\begin{array}{l}\text { Baja California } \\
\text { Sur }\end{array}$ & Tribunal electrónico & http://www.tribunalbcs.gob.mx \\
\hline Campeche & No & http://www.poderjudicialcampeche.gob.mx \\
\hline Chiapas & No & http://www.poderjudicialchiapas.gob.mx \\
\hline Chihuahua & Tribunal Virtual & http://www.stj.gob.mx \\
\hline $\begin{array}{l}\text { Coahuila de } \\
\text { Zaragoza }\end{array}$ & Expediente virtual & https://www.pjecz.gob.mx \\
\hline Colima & Edictos electrónicos & http://stjcolima.gob.mx/\#!/ \\
\hline $\begin{array}{l}\text { Ciudad de } \\
\text { México }\end{array}$ & No & http://www.poderjudicialcdmx.gob.mx \\
\hline Durango & No & http://pjdgo.gob.mx/consultas-frecuentes/ \\
\hline Guanajuato & Consultas electrónicas & https://www.poderjudicial-gto.gob.mx \\
\hline Guerrero & No & http://tsj-guerrero.gob.mx \\
\hline Hidalgo & No & http://www.pjhidalgo.gob.mx \\
\hline Jalisco & Sistema de consulta & http://www.stjjalisco.gob.mx \\
\hline México & Expediente virtual & http://web2.pjedomex.gob.mx \\
\hline $\begin{array}{l}\text { Michoacán de } \\
\text { Ocampo }\end{array}$ & Tribunal electrónico & $\begin{array}{l}\text { http://www.poderjudicialmichoacan.gob. } \\
\text { mx/web/ }\end{array}$ \\
\hline Morelos & No & http://tsjmorelos2.gob.mx/2016/ \\
\hline Nayarit & Diligencias en línea & http://www.tsjnay.gob.mx \\
\hline Nuevo León & $\begin{array}{c}\text { Tribunal virtual, juicio en } \\
\text { línea }\end{array}$ & https://www.pjenl.gob.mx \\
\hline Oaxaca & Tribunal virtual & https://www.tribunaloaxaca.gob.mx \\
\hline Puebla & Expediente virtual & http://www.htsjpuebla.gob.mx \\
\hline Querétaro & Expediente electrónico & https://www.tribunalqro.gob.mx \\
\hline Quintana Roo & Tribunal Virtual & http://www.tsjqroo.gob.mx \\
\hline San Luis Potosí & Notificaciones electrónicas & http://www.stjslp.gob.mx \\
\hline Sinaloa & Consulta electrónica & http://www.stj-sin.gob.mx \\
\hline Sonora & No & http://www.stjsonora.gob.mx \\
\hline Tabasco & No & http://tsj-tabasco.gob.mx \\
\hline
\end{tabular}




\begin{tabular}{|l|c|l|}
\hline Tamaulipas & Tribunal electrónico & http://www.pjetam.gob.mx \\
\hline Tlaxcala & No & http://www.tsjtlaxcala.gob.mx \\
\hline Veracruz & No & https://www.pjeveracruz.gob.mx \\
\hline Yucatán & Sirce web & http://www.tsjyuc.gob.mx \\
\hline Zacatecas & Consulta & http://www.tsjzac.gob.mx \\
\hline
\end{tabular}

Es menester señalar que las grandes corporaciones exaltan las virtudes del espacio público global: convivialidad, transparencia, igualdad y libertad. Frente a tal perspectiva que se erige en una sociedad "ordenada” en torno a la lógica del mercado, cabe preguntarse: ¿se trata de un nuevo espacio democrático? ¿Constituye un escenario alternativo de lo público, de lo social, de lo político, o constituye un espacio-límite a la idea de sentidos compartidos y proyectos colectivos? ¿Permite la red la construcción intersubjetiva de un espacio público democrático? ¿No es un ciudadano privado aquel de la red? ¿Qué forma toma la apropiación y significación de lo político entre los internautas? ${ }^{41}$

A partir de dichas interrogantes, el sistema de impartición de justicia debe utilizar las ventajas que ofrece la inteligencia artificial, como la interoperabilidad jurídica y tecnológica, para beneficio de la propia ciudadanía.

Lo anterior debe considerarse para la modernización judicial, al crear o diseñar un nuevo modelo organizacional y funcional de juzgado denominado juzgado virtual. El objetivo de este último es el aprovechamiento de las herramientas tecnológicas en la sustanciación de procesos judiciales. Debe buscar, entre otras cosas, que se dé comienzo a la migración ordenada del expediente físico al expediente digital. ${ }^{42}$

La principal característica operativa del juzgado virtual incide en que los negocios de su competencia se sustanciarán, desde su inicio hasta su conclusión, de manera digital, esto es, por medio del tribual virtual y de algunos otros programas informáticos de naturaleza análoga.

Los objetivos específicos de la justicia electrónica son: economía y concentración procesal; evitar el rezago de expedientes (para hacer más eficiente la impartición de la justicia) y reducir los costos de los procesos judiciales.

\footnotetext{
${ }^{41}$ LOZADA, MireYa, "Política en red y democracia virtual: la cuestión de lo público", Estudios Latinoamericanos sobre cultura y transformaciones sociales en tiempos de globalización 2, Buenos Aires, Clacso, 2001. [Consulta: 20 de mayo, 2017]. Disponible en: http://biblioteca.clacso.edu.ar/clacso/gt/20100914034214/10lozada.pdf

42 "Acuerdo General 14/2014, del Pleno del Consejo de la Judicatura del Estado relativo a la Creación del Juzgado Virtual de lo Familiar del Estado de Nuevo León, asi como a su jurisdicción, competencia, fecha de inicio de funciones y reglas de operación", Poder Judicial del Estado de Nuevo León. [Consulta: 13 de junio, 2017]. Disponible en: https://www.pjenl.gob.mx/ConJud/Acuerdos/2014/Acuerdo14.pdf
} 
La verdadera democracia electrónica consiste en fortalecer al máximo, gracias a las formas de comunicación interactiva ofrecidas por el ciberespacio, la expresión y elaboración de los problemas de las ciudades por los propios ciudadanos, la autoorganización de las comunidades locales y la participación en las deliberaciones por parte de los grupos verdaderamente afectados. ${ }^{43}$

Es de citar que este tipo de pactos no es más que el inicio de lo que en breve será un hecho tangible, como lo es el juzgado virtual dentro del Poder Judicial del Estado. La constante de los nuevos tiempos es el cambio, y la impartición de justicia no es ajena a la misma: debe ser transparentada del todo.

El establecimiento del juzgado virtual representa un avance significativo en nuestra manera de entender la labor jurisdiccional: el acceso a juzgados, en el particular de los del estado de Nuevo León, se encuentra prácticamente disponible a cualquier día y hora, desde cualquier parte del mundo, gracias a una debida planeación y al establecimiento de las herramientas y sistemas informáticos precisos.

Otra es la etapa de operación desde la entrada en operación de la primera fase. Ésta permitió su amplia adopción por la institución, y se requirió acceso público y privado a través de internet. Con ello aumentaron las exigencias de seguridad, estabilidad, continuidad, desempeño, disponibilidad de horario y escalabilidad.

No se descuidó la etapa de mejora continua. Una vez logrado el primer nivel de operación, en donde se aseguran formalmente los aspectos de continuidad, disponibilidad, crecimiento y seguridad, se pasa a esta etapa. Esto es su operación organizacional, especialmente el de la creación de una cultura que inspire a las personas a emplear procesos y herramientas tecnológicas para mejorar la función informática.

Es por ello que se labora en una mejora continua, desde los retos inmediatos hasta la ampliación del alcance del tribunal virtual, mejorar las aplicaciones a futuro y contribuir con las acciones de alineamiento y arquitectura implantando una plataforma de inteligencia institucional para monitorear el 150 desempeño de la administración de justicia. Debe haber regulaciones claras, o que pretenden ser claras, tales como:

\footnotetext{
43 "Acuerdo General 14/2014, del Pleno del Consejo de la Judicatura del Estado relativo a la Creación del Juzgado Virtual de lo Familiar del Estado de Nuevo León, así como a su jurisdicción, competencia, fecha de inicio de funciones y reglas de operación", Poder Judicial del Estado de Nuevo León. [Consulta: 13 de junio, 2017]. Disponible en: https://www.pjenl.gob.mx/ConJud/Acuerdos/2014/Acuerdo14.pdf
} 
Reglas de operación virtual. Los asuntos que se refiere el punto tercero de este Acuerdo General, serán tramitados en su totalidad de manera virtual, de acuerdo con lo ordenado en el segundo título especial, denominado "Del Tribunal Virtual”, del Código de Procedimientos Civiles del Estado.

El juzgado virtual de lo familiar privilegiará la existencia del expediente digital; solo en casos de imperiosa necesidad y cuando haya razones que así lo justifiquen conservará temporalmente el expediente físico.

Presentación de demandas y promociones. La presentación de las demandas y promociones deberá efectuarse de forma electrónica cuando se trate de dependencias con facultades para iniciar vía Tribunal Virtual o a través del sistema especializado que corresponda, los procedimientos a que se refiere este Acuerdo General.

Cualquier otra forma de presentación se hará por conducto de las oficialías de partes o juzgados en donde no se cuente con aquellas. En el caso de que se presente la promoción física o se acompañen documentos, se procederá a su digitalización inmediata, devolviéndose los originales a efecto de que queden en custodia para cuando se requieran.

Las notificaciones serán efectuadas, preferentemente, por medios electrónicos. Aquellas que, por alguna razón, no pueda practicar el Tribunal Virtual deberán ser materializadas por conducto de la Unidad de Medios de Comunicación, la cual, para efectos del juzgado virtual de lo familiar, tendrá cobertura en todo el estado, y enviará la constancia electrónica de su materialización.

La comunicación entre juzgados deberá entablarse entre los juzgados que integran los diversos distritos judiciales de forma electrónica. Cuando no sea posible, el juzgado virtual de lo familiar deberá digitalizar e incorporar al expediente electrónico las constancias físicas que se hayan recabado para tales efectos.

En el tema de la temporalidad de los actos procesales, serán considerados en tiempo los recibidos hasta las veinticuatro horas del último día. Si los sistemas electrónicos fueran inaccesibles por razones técnicas, el plazo se prorrogará automáticamente hasta el primer día hábil siguiente a de la solución del problema.

Ahora bien, respecto a la garantía de acceso, se regula que en aquellos casos en que alguna de las partes alegue no tener acceso a la tecnología de grabación o respaldos informáticos por carencia de recursos o desconocimiento, $o$ 
personas con capacidades diferentes, el juzgado deberá imprimir la resolución o facilitar a la parte el acceso con recursos institucionales.

Para el rubro de desahogo de pruebas en forma electrónica que deban que requieran intervención judicial y se tratare de asuntos en donde los y las interesadas se encuentren en los distintos del primero al cuarto, se podrá llevar a cabo mediante comparecencia personal al juzgado. En caso contrario, se practicarán vía exhorto, a través de la plataforma exhortos.gob.mx, en donde será responsabilidad del juzgado virtual el señalamiento de una fecha y hora específica para llevar a cabo la prueba, por conducto del programa de videoconferencias.

Se regula con claridad que el juez y el secretario que corresponda deberá firmar en forma electrónica los acuerdos, sentencias y demás actuaciones judiciales. Además, señala que para el caso de temor fundado de que las actuaciones hubieren sufrido alguna alteración sin la autorización correspondiente, deberá informarse de forma inmediata al Consejo de la Judicatura.

Pone en marcha, dentro del proyecto, el proceder de quienes imparten la justicia y desnuda a las y los ciudadanos las acciones de sus actores legales para darles mayor confianza en el uso de la herramienta que es la informática. ${ }^{44}$

Como inconvenientes del uso documento-papel, encontramos: tiende a deteriorarse rápidamente por la acción del tiempo, ocupa un creciente volumen de espacio físico, la duplicación de los expedientes en papel es incómoda y costosa.

\section{Conclusiones}

El aprovechamiento de las herramientas tecnológicas en la sustanciación de procesos judiciales es con el fin de dar comienzo a la migración vivencial de manera ordenada y dictaminada del expediente físico al expediente electrónico o digital.

Las tecnologías de la información y la comunicación también permiten el trabajo colaborativo que persigue favorecer el intercambio de información entre operadores, así como el trabajo en común en el seno de una comunidad de usuarios e usuarias. Asimismo, hay que tener suficiente capacidad de los servidores de internet, aplicaciones web bien elaboradas, un soporte técnico permanente, eficiente y eficaz, un sistema amigable, seguro, compatible y presupuestal.

\footnotetext{
44 "Digitaliza Poder Judicial sus procesos", Periodistas en línea. [Consulta: 13 de junio, 2017]. Disponible en: http:// www.periodistasenlinea.org/18-09-2008/17205
} 
En el futuro, será posible llegar a ver procesos judiciales en los que el papel sea prescindible. Será suficiente el empleo de documentos digitales o electrónicos con mayor eficiencia y eficacia, hasta llegar a la llamada justicia sin papel.

Los objetivos específicos de la justicia electrónica son: economía y concentración procesal; evitar el rezago de expedientes hace más eficiente la impartición de la justicia y reduce los costos de los procesos judiciales. Todo esto se conseguirá con la utilización de las Tic como herramienta de administración de todo el proceso judicial.

\section{Bibliografía}

“Acuerdo General 14/2014, del Pleno del Consejo de la Judicatura del Estado relativo a la Creación del Juzgado Virtual de lo Familiar del Estado de Nuevo León, así como a su jurisdicción, competencia, fecha de inicio de funciones y reglas de operación”, Poder Judicial del Estado de Nuevo León. [Consulta: 13 de junio, 2017]. Disponible en: https://www.pjenl.gob.mx/ConJud/Acuerdos/2014/Acuerdo14.pdf

Azúa Reyes, Sergio, Los principios generales del derecho, México, Porrúa, 2001.

BARRAgÁn, Julia, Informática y decisión judicial, México, Fontamara, 1994.

BuENO DE MATA, FEDERICo, “La prueba electrónica: importancia, problemática procesal y reconocimiento jurisprudencial de la prueba capital del siglo xxı”, en Pilar Lasala Calleja (ed.), La administración electrónica como herramienta de inclusión digital, España, Prensas Universitarias de Zaragoza, 2011. [Consulta: 12 de junio, 2017]. Disponible en: http://www.egov.ufsc.br/portal/sites/default/files/lefis_13_ok.pdf

Cerillo, Agustí, "E-justicia: las tecnologías de la información y el conocimiento al servicio de la justicia iberoamericana en el siglo xxi”, Revista de Internet, Derecho y Politica, núm. 4. [Consulta: 1 de junio, 2017]. Disponible en: http://www.uoc.edu/idp/4/dt/esp/cerrillo1.pdf

“Digitaliza Poder Judicial sus procesos”, Periodistas en línea. [Consulta: 13 de junio, 2017]. Disponible en: http://www.periodistasenlinea.org/18-09-2008/17205

Fierro Rodríguez, Diego, "El papel es necesario en la actual Administración de Justicia”, Hay Derecho. Por una conciencia cívica. [Consulta: 12 de junio, 2017]. Disponible en: http://hayderecho.com/2015/08/01/el-papel-es-necesario-en-la-actual-administracion-de-justicia/

Fix Fierro, Héctor y Muñoz de Alba, Marcia, “El sistema unAm-Jure. Hoy”, Diálogos sobre Informática Jurídica. [Consulta: 27 de mayo, 2017]. Disponible en: https://archivos.juridicas.unam.mx/www/bjv/libros/2/723/5.pdf 
García Barrera, Myrna Elia, “Justicia electrónica o Ciber justicia, El Tribunal Virtual de Nuevo León”. [Consulta: 2 de junio, 2017]. Disponible en: https://archivos.juridicas.unam.mx/www/bjv/libros/6/2958/16.pdf

GonzÁlez CAmpo, Francisco de Asís, “Arquitectura de la administración judicial electrónica española: estado actual y perspectivas de futuro”, en Pilar Lasala Calleja (ed.), Derecho y Tecnologías Avanzadas, España, Prensas Universitarias Zaragoza, 2013.

Guibourg, Ricardo, Allende, Jorge y Campanella, Elena, Manual de informática jurídica, Argentina, Astrea, 1996.

HAYEK, FrIEDRICH, Los fundamentos de la libertad, tomo 1, Valencia, España, Fomento de Cultura, 1961.

Londoño SEPÚlVEda, NÉSTOR RaÚl, "El uso de las TIC en el proceso judicial: una propuesta de justicia en línea”, Revista Facultad de Derecho y Ciencias Politicas. [Consulta: 1 de junio, 2017]. Disponible https://revistas.upb.edu.co/index. php/derecho/article/view/1033/931

LóPeZ de OÑATe, Flavio, La certeza del derecho, Buenos Aires, Argentina, Ediciones Jurídicas Europa-América, 1953.

López VAlencia, Virginia, "La justicia digital. El nuevo paradigma”, Gobierno del Estado de Guerrero 2015-2021. [Consulta: 13 de junio, 2017]. Disponible en: http://i.guerrero.gob.mx/uploads/2016/02/LA-JUSTICIA-DIGITAL.pdf

LozAdA, Mireya, "Política en red y democracia virtual: la cuestión de lo público", Estudios Latinoamericanos sobre cultura y transformaciones sociales en tiempos de globalización 2, Buenos Aires, Clacso, 2001. [Consulta: 20 de mayo, 2017]. Disponible en: http://biblioteca.clacso.edu.ar/clacso/ gt/20100914034214/10lozada.pdf

Montesinos García, Ana, "Cuestiones actuales de derecho y tecnologías de la información y la comunicación (TIC)”, Revista Aranzadi Derecho de las Nuevas Tecnologías, núm. 4.

Perales SAnz, José Luis, La seguridad jurídica en las transacciones electrónicas, Seminario del Consejo General del Notariado en la UIMP, Madrid, Civitas, 2002.

PÉREZ Ruíz, CARLos, La construcción social del derecho, España, Universidad de Sevilla, 1996.

Téllez Valdés, Julio, Derecho informático, México, unAm. [Consulta: 25 de mayo, 2017]. Disponible en: https://archivos.juridicas.unam.mx/www/bjv/libros/1/313/4.pdf

"Tesis Jurisprudencial número 22/2016 de la Primera Sala de la Suprema Corte de Justicia de la Nación”, Suprema Corte de Justicia de la Nación. Consulta: 20 de mayo, 2017]. Disponible en: https://sjf.scjn.gob.mx/sjfsist/paginas/DetalleGeneralV2.aspx?Clase=DetalleTesisBLCtID $=2011430 \&$ Semanario $=0$ 